\title{
Evaluation of College Students' Innovation and Entrepreneurship Ability based on Cloud Theory
}

\author{
Xinghuo Wan, Yan Sun, Dongqin Gao, Shuo Li \\ College of Science, North China University of Science and Technology, Tangshan 063210, Hebei, China
}

\begin{abstract}
In this paper, the evaluation index of innovation and entrepreneurship ability is established, with the historical data of College Students' innovation and entrepreneurship and the survey results of experts, the quantitative evaluation of College Students' innovation and entrepreneurship ability is realized. which provides a reference for the evaluation of College Students' innovation and entrepreneurship ability. At the same time, a beneficial exploration is carried out, that includes the practice of the new development concept of innovation in education and the assessment by school managers and teachers of students' innovative entrepreneurial capacity during formation stages and long-term or periodicity.
\end{abstract}

Keywords: Cloud model, Evaluation of innovation and entrepreneurship ability, Weight.

\section{Introduction}

As Premier Li Keqiang[1] emphasized the idea of "mass entrepreneurship and innovation", improving college students' innovation and entrepreneurship ability is the top priority. Therefore, it is necessary to establish an effective evaluation system and relevant incentive policies. Examples of different evaluation contents and methods are verified and compared in literature[2-10]. The evaluation methods include fuzzy comprehensive evaluation method[11], pair analysis and emerging machine learning methods such as support vector machine[12]. The above models and methods express the system uncertainty by constructing linear functions. How to give consideration to randomness and fuzziness is the difficulty of the comprehensive evaluation method. Academician Li Deyi[13] proposed the cloud theory, which can integrate the fuzziness and randomness of language qualitative concepts. It is an important tool for studying uncertainty and has good advantages and characteristics in solving the problem of comprehensive evaluation of qualitative and quantitative indicators. This paper is based on this.

How to correctly recognize their innovation and entrepreneurship ability and how to identify entrepreneurial opportunities can be effectively improved through the objective evaluation of College Students' innovation and entrepreneurship ability. At the same time, it is conducive to universities to improve teaching methods and means according to the evaluation results. In order to objectively understand the influencing factors of innovation and entrepreneurship ability and guide students to improve innovation and entrepreneurship ability through quantitative analysis, this paper uses questionnaire survey method and cloud model to comprehensively evaluate undergraduate innovation and entrepreneurship ability.

\section{Introduction to Cloud Model}

Academician Li Deyi proposed the cloud model in the 1990s. Combined with the principles of fuzzy mathematics and traditional probability theory, he comprehensively described the fuzziness and randomness of events through cloud theory. The cloud model is defined as follows: let $U$ be a quantitative domain expressed by accurate values, and $C$ be a qualitative concept on $U$ (expressed by digital features), if the quantitative value $x \in U$; And $X$ is a random realization of qualitative concept $C$, and the uncertainty $\mu(x)$ of $x$ to $C$ is a random number with stable tendency.

$$
\begin{gathered}
\mu: U \rightarrow[0,1] \\
\forall x \in U, x \mapsto \mu(x)
\end{gathered}
$$

Then the distribution of $x$ on universe $U$ is called cloud, and each $x$ is called a cloud drop.

Where expectation $E x$ is the expectation of cloud in space, which represents the central value of fuzzy concept in the universe, and entropy $E n$ reflects the randomness of qualitative concept and the dispersion of cloud droplets; Hyper entropy $\mathrm{He}$ is a description of the uncertainty measure of entropy, which reflects the degree of cloud dispersion and cloud thickness.

Let $C$ be the qualitative concept on the universe $U$, if $x$ obeys the normal distribution with mean $E x$ and variance $E n^{\prime}$, and the random variable $E n^{\prime}$ also obeys the normal distribution, with mean $E n$ and variance $H^{2}$. Then the uncertainty formula of $x$ is:

$$
\mu(x)=\exp \left(-\frac{(x-E x)^{2}}{2 E n^{2}}\right) U
$$

Then $x$ is called the normal cloud on universe $U$. The above formula shows that determining the certainty of cloud droplets by solving the normal fuzzy membership is also a method to determine the quantitative value of cloud droplets by the standard normal distribution function, so the normal cloud model also has the characteristics of fuzziness and randomness.

\section{Cloud Generator}

Cloud generator can obtain quantitative information from qualitative concepts of language, including forward and reverse cloud generators. The reverse cloud generator can convert quantitative data into qualitative concepts represented by $E x, E n$ and $\mathrm{He}$. A classification method of the reverse cloud generator is to distinguish according to the membership 
degree. The operation diagram of the reverse cloud generator is shown in Figure 1.

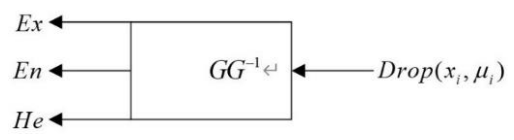

Figure 1: Operation diagram of reverse cloud generator

The algorithm is introduced as follows:

Input: cloud droplets $(n)$

Output: $E x, E n$ and $H e$ of $n$ cloud droplets:

(1) Calculate the input mean value $\bar{X}=\frac{1}{n} \cdot \sum_{i=1}^{n} x_{i}$ and variance $S^{2}=\frac{1}{n-1} \cdot \sum_{i=1}^{n}\left(x_{i}-\bar{X}\right)^{2}$

(2) Calculate the expected value $E x=\bar{X}$;

(3) Calculate entropy $E n=\sqrt{\frac{\pi}{2}} \frac{1}{n} \cdot \sum_{i=1}^{n}\left(\mathrm{x}_{i}-\mathrm{Ex}\right)$;

(4) Calculate the super entropy $H e=\sqrt{S^{2}-E n^{2}}$

Considering that the normal cloud model has unique digital characteristics and strong universality, this paper uses the normal cloud model for comprehensive evaluation, and uses the normal cloud generator to establish the mapping between quantitative and qualitative.

\section{Construction of Evaluation Model Based on Cloud Theory}

4.1 The Evaluation Index System of College Students' Innovation and Entrepreneurship Ability

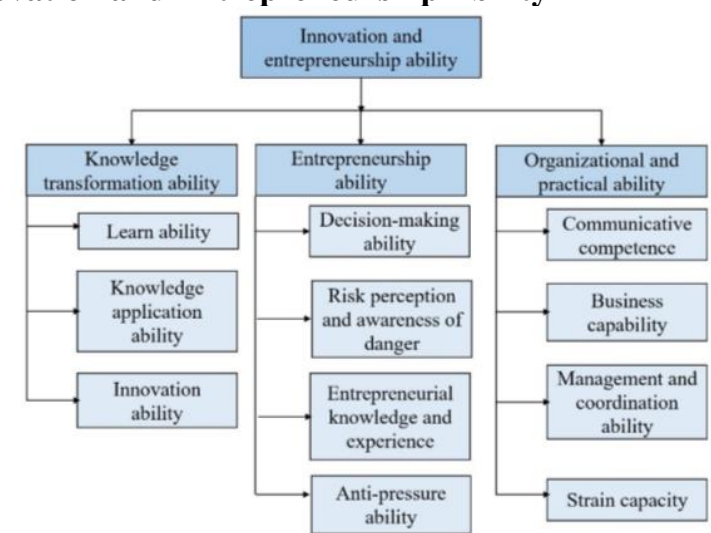

Figure 2: Index system of College Students' innovation and entrepreneurship ability

Scientific and objective evaluation of College Students' innovation and entrepreneurship ability is required. Literature[14] puts forward that innovation and entrepreneurship ability is a collection of knowledge, practical ability and innovation ability. Literature[15] integrates it into knowledge structure, organizational planning, social ability and other aspects from the perspective of management. Combined with the above literature and considering the actual situation of current college students, according to the index selection principle, entrepreneurship, entrepreneurial ability and basic ability are selected as the secondary index to establish the evaluation system, as shown in Figure 2.

\subsection{Evaluation Algorithm of College Students' Innovation and Entrepreneurship Ability}

(1) In the historical database of innovation and entrepreneurship projects, a certain amount of innovation and entrepreneurship achievements and research results of college students of the same grade in our university are selected as training data, and the cloud transformation algorithm is used to obtain the qualitative concepts $\mathrm{Ai}(\mathrm{Ex}, \mathrm{En}, \mathrm{He})$ representing different levels of index ability; The weight value of each three-level index is calculated by entropy weight method and the weight vector $w$ is obtained.

(2) The data of each student to be evaluated is processed by the reverse normal cloud generator to obtain the corresponding qualitative concept $\mathrm{Ci}(\mathrm{Ex}, \mathrm{En}, \mathrm{He})$. Repeat this step for each student's grade.

(3) Take each Ex obtained in step 2 as the input of $x$ condition cloud generator, calculate the membership degree of each concept $A i$, and The membership degree matrix is obtained.

(4) The weight vector $w$ calculated by entropy weight method and the membership matrix based on cloud model are weighted and transformed to obtain the comprehensive certainty. Finally, the sample grade is determined according to the maximum membership principle.

\section{Empirical Analysis of Evaluation Model Based on Cloud Theory}

\subsection{Determination of Index Threshold}

According to the above established index system, the indicator is classified by cloud transform ideas, and the digital characteristics of the cloud model are obtained by cloud change. The inspection shows that most data meet the normal distribution, so this article uses a normal cloud, and the research object is the survey data of graduate students' innovation and entrepreneurship ability of North China University of Science and Technology, with strong independence among the data.

Taking the learning ability as an example, the digital characteristics are determined as $(3.38,1.228,0.354)$ through the reverse cloud generator. After the grade distribution map is obtained, it is divided into five grades through the grading standard, that is, grade I corresponds to "weak", grade II to "general", grade III to "strong", grade IV to "very strong" and grade V to "super". The thresholds corresponding to the five grades of learning ability are obtained. The grading threshold standard is shown in Table 1 below.

Table 1: Index threshold classification standard

\begin{tabular}{cc}
\hline Grade & Threshold Value \\
\hline I & {$[0, E x-1 / 2 E n]$} \\
II & {$[E x-1 / 2 E n, E x]$} \\
III & {$[E x, E x+1 / 2 E n]$} \\
IV & {$[E x+1 / 2 E n, E x+E n]$} \\
V & {$[E x, \infty]$} \\
\hline
\end{tabular}




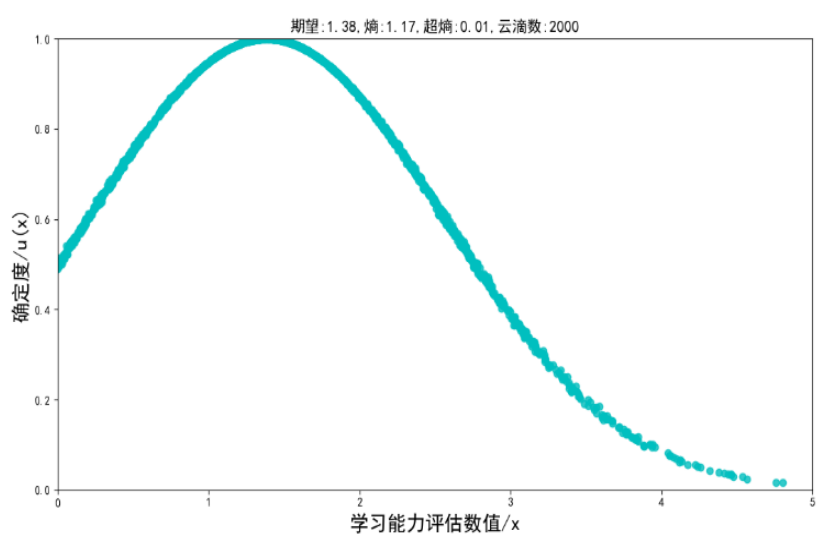

Figure 3: Distribution map of learning ability level

\subsection{Determination of Index Level Based on Cloud Model}

The digital characteristics of the evaluation indexes in the cloud model are calculated according to the following formula:

$$
\begin{aligned}
& E x_{i j}=\left(x_{i j}^{1}+x_{i j}^{2}\right) / 2 \\
& \exp \left[-\frac{\left(x_{i j}^{1}+x_{i j}^{2}\right)^{2}}{8\left(E n_{i j}\right)^{2}}\right] \approx 0.5 \\
& E n_{i j}=\left(x_{i j}^{1}+x_{i j}^{2}\right) / 2.355
\end{aligned}
$$

Where $x_{i j}^{1}$ and $x_{i j}^{2}$ respectively represent the maximum and minimum values of an index grade. The boundary values are adjusted according to the actual boundary value of the index. $H e$ is taken from experience. According to reference materials and expert suggestions, this paper takes 0.01 .

Finally, after the digital characteristics of the five level indicators corresponding to each ability are brought into the forward cloud generator, the cloud maps of each level of each index are drawn. Taking learning ability as an example, the five level cloud maps are integrated as shown in Figure 4.

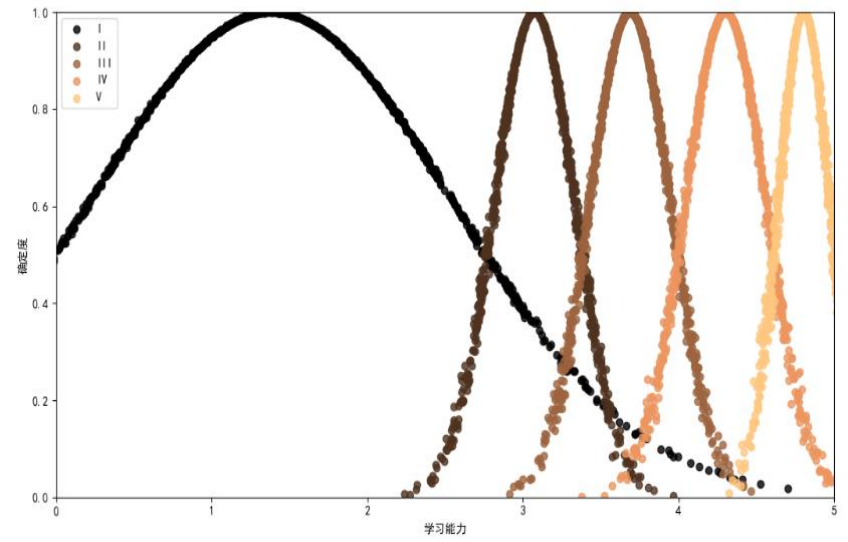

Figure 4: Cloud chart of learning ability threshold level

Finally, the cloud model digital features of 13 capabilities corresponding to five level indicators are obtained. As shown in Table 2.

\subsection{Calculated Weight by Entropy Weight Method}

Entropy weight method, as a more objective weighting method, determines the weight according to the information provided by the observation data.

Ten students in the historical database of innovation and entrepreneurship projects are randomly selected as samples. Ten experts inside and outside the school score the samples, build a judgment matrix, and bring it into the entropy weight formula to obtain the weight matrix, as shown in Table 3.

Table 2: Five level digital characteristics of innovation and entrepreneurship evaluation indicators

\begin{tabular}{|c|c|c|c|c|c|c|c|c|c|c|c|}
\hline & $\begin{array}{c}\text { Learn } \\
\text { ability }\end{array}$ & $\begin{array}{c}\text { Knowledg } \\
\text { e } \\
\text { applicatio } \\
\text { n ability }\end{array}$ & $\begin{array}{c}\text { Innovation } \\
\text { ability }\end{array}$ & $\begin{array}{c}\text { Decision- } \\
\text { making } \\
\text { ability }\end{array}$ & $\begin{array}{c}\text { Risk } \\
\text { perception } \\
\text { and } \\
\text { awareness } \\
\text { of danger }\end{array}$ & $\begin{array}{l}\text { Entreprene } \\
\text { urial } \\
\text { knowledge } \\
\text { and } \\
\text { experience }\end{array}$ & $\begin{array}{l}\text { Anti-press } \\
\text { ure ability }\end{array}$ & $\begin{array}{c}\text { Communi } \\
\text { cative } \\
\text { competenc } \\
\mathrm{e}\end{array}$ & $\begin{array}{l}\text { Business } \\
\text { capability }\end{array}$ & $\begin{array}{l}\text { Managem } \\
\text { ent and } \\
\text { coordinati } \\
\text { on }\end{array}$ & $\begin{array}{c}\text { Strain } \\
\text { capacity }\end{array}$ \\
\hline weight & 0.062529 & 0.111761 & 0.074352 & 0.072338 & 0.235003 & 0.043227 & 0.055521 & 0.075845 & 0.06356 & 0.075845 & 0.130019 \\
\hline
\end{tabular}

\begin{tabular}{cccccc}
\hline & Grade I & Grade II & Grade III & Grade IV \\
\hline Learn ability & $(1.38,1.174,0.01)$ & $(3.07,0.261,0.01)$ & $(3.69,0.261,0.01)$ & $(4.30,0.261,0.01)$ & $(4.80,0.166,0.01)$ \\
Knowledge application ability & $(1.34,1.139,0.01)$ & $(2.98,0.254,0.01)$ & $(3.58,0.254,0.01)$ & $(4.18,0.254,0.01)$ & $(4.74,0.223,0.01)$ \\
Innovation ability & $(1.46,1.240,0.01)$ & $(3.22,0.255,0.01)$ & $(3.82,0.255,0.01)$ & $(4.42,0.255,0.01)$ & $(4.86,0.119,0.01)$ \\
Decision-making ability & $(1.70,1.446,0.01)$ & $(3.64,0.202,0.01)$ & $(4.12,0.202,0.01)$ & $(4.59,0.202,0.01)$ & $(4.92,0.072,0.01)$ \\
Risk perception and awareness of danger & $(1.14,1.120,0.01)$ & $(2.89,0.176,0.01)$ & $(3.31,0.176,0.01)$ & $(3.72,0.176,0.01)$ & $(4.46,0.456,0.01)$ \\
Entrepreneurial knowledge and experience & $(1.45,1.234,0.01)$ & $(3.21,0.261,0.01)$ & $(3.81,0.261,0.01)$ & $(4.44,0.261,0.01)$ & $(4.87,0.106,0.01)$ \\
Anti-pressure ability & $(1.58,1.339,0.01)$ & $(3.40,0.207,0.01)$ & $(3.88,0.207,0.01)$ & $(4.37,0.207,0.01)$ & $(4.81,0.164,0.01)$ \\
Communicative competence & $(1.47,1.249,0.01)$ & $(3.21,0.230,0.01)$ & $(3.75,0.229,0.01)$ & $(4.29,0.229,0.01)$ & $(4.78,0.187,0.01)$ \\
Business capability & $(1.48,1.261,0.01)$ & $(3.24,0.234,0.01)$ & $(3.80,0.234,0.01)$ & $(4.35,0.234,0.01)$ & $(4.81,0.161,0.01)$ \\
Management and coordination ability & $(1.55,1.313,0.01)$ & $(3.36,0.224,0.01)$ & $(3.88,0.224,0.01)$ & $(4.41,0.224,0.01)$ & $(4.84,0.139,0.01)$ \\
Strain capacity & $(1.49,1.263,0.01)$ & $(3.24,0.224,0.01)$ & $(3.76,0.224,0.01)$ & $(4.29,0.224,0.01)$ & $(4.78,0.190,0.01)$ \\
\hline
\end{tabular}

Table 3: Index weight of College Students' innovation and entrepreneurship ability

Table 3 shows that in the knowledge transformation ability, the knowledge application ability accounts for $11.126 \%$, among entrepreneurial ability, perception of risk and sense of hardship account for the highest proportion, which is also the largest one among all indicators, accounting for $23.5 \%$. In organizational practice, the adaptability accounts for $13 \%$. Through the proportion of entropy weight, we get that the higher risk awareness and flexibility for college students' innovation and entrepreneurship are required in new era, which is not only related to the flexibility of contemporary college students, also closely related to the current tight economic and social environment.

\section{$5.4 x$ Conditional Cloud Generator}

Uses the qualitative concept, weight value and $x$ conditional cloud model of each evaluation index obtained in the above steps to conduct qualitative evaluation on five students to be tested. The $X$ conditional cloud model is to test the digital eigenvalue $E x$ of each index of the student and bring it into the 
positive cloud generator of each level of the corresponding index. As the input of $x$, the membership degree of the student at five levels under a certain ability is calculated. Then, the membership values of different capabilities at the same level are weighted, and the corresponding level is determined according to the maximum membership principle.

Finally, we get the comprehensive ability membership of the five students, as shown in Table 4 below.

Table 4: Comprehensive uncertainty of sample innovation and entrepreneurship ability level

\begin{tabular}{cccccc}
\hline $\begin{array}{c}\text { Sample } \\
\text { Number }\end{array}$ & Grade I & Grade II & Grade III & Grade IV & Grade V \\
\hline 1 & 0.614372 & 0.321576 & 0.0938 & 0.03436 & 0.001413 \\
2 & 0.270386 & 0.260988 & 0.288413 & 0.180919 & 0.140237 \\
3 & 0.592778 & 0.391289 & 0.086367 & 0.010378 & 0.001423 \\
4 & 0.111038 & 0.047148 & 0.197398 & 0.130568 & 0.284264 \\
5 & 0.126411 & 0.068369 & 0.070608 & 0.132761 & 0.316929 \\
\hline
\end{tabular}

It can be concluded that the innovation and entrepreneurship ability of classmate 1 and classmate 3 is weak, belonging to grade I, the ability of classmate 4 and classmate 5 is very strong, belonging to grade $\mathrm{V}$, the ability membership of classmate 2 is not obvious in the first three grades, and the comprehensive evaluation of innovation ability is relatively weak.

\section{Conclusions and Suggestions}

Experiment proves that we can explore more information about the improvement of innovation and entrepreneurship ability through the cloud theory evaluation method, make the evaluation results more comprehensive and specific, and comprehensively reflect the uncertainty and randomness of the evaluation. Whether students, teachers or universities, we should have a targeted goal, focus on breakthrough and cultivate students' innovation and entrepreneurship ability. Therefore, this evaluation model has certain practical significance and promotion value.

The distribution of the data is obtained by using the reverse cloud generator, and the threshold classification is carried out by using the cloud transformation theory. Finally, the hierarchical cloud model is determined, which makes the classification more scientific.

The model uses entropy weight method to calculate the index weight, which makes the evaluation more objective; and find out the key points of cultivating innovative ability from the size of weight: cultivate students' ability of application and practical; Strengthen students' risk perception ability and encourage students to observe the general trend of social economy; At the same time, students should strengthen practice and improve their adaptability in dealing with various matters.

\section{Acknowledgement}

This paper is supported by the Basic Research Project of Science and Technology (Natural Science) (JQN2021024).
[1] Government work report[N]. People's Daily, 2015-0317(001)

[2] Ge Fuyou. Construction of evaluation index system of College Students' innovation ability in Higher Vocational Colleges[J]. China Statistics, 2017(12): $55-56$.

[3] Li Ying. Construction of innovation consciousness and ability evaluation system for higher vocational students[J]. Vocational Education Forum, 2013(12): 66-68.

[4] Fu Dan, He Zhifang, Ke Yu. Application of extension comprehensive evaluation method in the evaluation of College Students' innovation ability[J]. Educational Academic Monthly, 2015(08): 47-52.

[5] Qi Shuyu, Fang Yaoyao. Construction and design of evaluation index system for innovation and entrepreneurship ability of engineering college students[J]. Research on Science and Technology Management, 2017, 37(24): 68-74.

[6] Liu Chun. Research on the evaluation system of Higher Vocational Students' innovation and entrepreneurship ability based on analytic hierarchy process[J]. Adult Education, 2015, 35(04): 55-57.

[7] Qian Chunlin, Tian Liyan, Zhou Liangying, Ma Shuliang. Fuzzy evaluation model for innovative training of Applied Talents in Higher Vocational Colleges[J]. Journal of Suzhou Vocational University, 2004(04): 4-8.

[8] Li Li. Evaluation and analysis of Higher Vocational Students' Innovative Ability-Discussion Based on analytic hierarchy process and fuzzy comprehensive evaluation method[J]. Adult Education, 2014, 34(09): 71-74.

[9] Bai Zhifan. Research on students' innovative ability in Higher Vocational Colleges[D]. Tianjin Vocational and Technical Normal University, 2016.

[10] Yin Mulan, Zhang Jun. Research on Higher Vocational Students' innovation evaluation system based on analytic hierarchy process[J]. Journal of Qingdao Ocean Crew Vocational College, 2018, 39(04): 53-55.

[11] Shen Jinchang, Du Shuxin, Luo Yi, Luo Jiyang, Yang Qian, Chen Zhifeng. Fuzzy comprehensive evaluation method based on cloud model and its application[J]. Fuzzy Systems and Mathematics, 2012, 26(06): 115-123.

[12] Zhao Keqin, Xuan Aili. Set Pair Theory-A new method and application of uncertainty theory[J]. Systems Engineering, 1996(01): 18-23+72.

[13] Li Deyi, Liu Changyu, Du Ying, Han Xu. Uncertain artificial intelligence[J]. Journal of Software, 2004(11): 1583-1594.

[14] Zhang Kun. Discussion on the cultivation of College Students' innovation and entrepreneurship ability [J]. Guide to Ideological and Theoretical Education, 2015(11): 137-139.

[15] Chen Chen. On the connotation and influencing factors of College Students' entrepreneurial ability[J]. Theoretical Observation, 2011(05): 145-146.

\section{References}

